\title{
Prediction of dynamic responses of floating structures using NARX with mirroring technique
}

\author{
Ruly Irawan ${ }^{1, *}$, Mohd Shahir Liew ${ }^{1}$, Montasir Osman Ahmed Ali ${ }^{1}$, \\ and Ahmad Mohamad Al Yacouby ${ }^{1}$ \\ ${ }^{1}$ Department of Civil and Environmental Engineering, Universiti Teknologi PETRONAS, 32610 Seri \\ Iskandar, Malaysia
}

\begin{abstract}
Displacements, velocities and accelerations of Six Degree of freedom of a single floating structure was predicted using Time Series NARX feedback neural Networks. The nonlinear autoregressive network with exogenous inputs (NARX) is a recurrent dynamic network, with feedback connections enclosing several layers of the network is based on the linear ARX model, which is commonly used in time-series modelling is used in this study. Time series data of displacements of a single floating structure was used for training and testing the ANN model. In the training stage, this time series data of environment parameters was used as input and dynamic responses was used as target. Benchmarking result and error prediction was compared between two techniques of Neural Network training. The prediction result of the model responses can be concluded that NARX with mirroring technique increase the accuracy and can be used to predict time series of dynamic responses of floating structures.
\end{abstract}

\section{Introduction}

Dynamic responses of floating structure are highly non-linear and complex relationship with many parameters. Environment load such as random waves, winds, and currents are the biggest factor that affects the structure behaviour. Damping and added mass for floating structure are based on frequency domain. Damping and added mass parameters are the most important factors in calculating floating structure responses and its stabilities. Excessive drift forces due to irregular waves is known to cause mooring failures, loses its stability, stop oil production etc. To achieve maximum performance during production, prediction on floating structure behaviour during environmental load is necessary. However, it is known that calculation that involve fluid-structure interactions are very expensive. Numerical simulation of floating structure responses depends on several related factors as described above, therefor reliable prediction both input and output are significantly data-demanding. This study focuses on prediction of dynamic responses of a single floating structure using NARX Feedback Neural Network [1-4].

Artificial Intelligent such as Neural Network method has been used for years, especially in information technology engineering [7-5]. Neural Network techniques is used to

*Corresponding author: ruly_17005131@utp.edu.my 
simulate and forecast problems in offshore engineering recently and has been applied successfully in the estimation of nonlinear mooring and riser tension, mooring design parameters, tandem ship dynamics, and hybrid ANN-FEM [8-11]. ANN well known methodology that has been carried out with comprehensive review by experts, performed well to approach to nonlinear behaviour modelling [12-18]. Today, many researchers improve the speed and accuracy of Artificial Neural Network method, therefor, this paper is encouraged to develop an ANN model with Time Series NARX Feedback Neural Networks for predicting time series dynamic responses of floating structure [19-33].

The uses of ANN are currently widespread in many applications related to engineering problems [34,35]. Presently they have also been employed to offshore engineering problems, such as prediction of sea-state characteristics, dynamic positioning systems, etc [36-38]. Recently, Quéau et al. [39] used an innovative approach when ANN to study the fatigue behaviour of steel catenary risers (SCR), while Kim [40,41] used ANN to estimate the dynamic responses of catenary riser with the use of a meta-model based on quadratic Volterra kernels.

ANNs is used in the analysis and design of mooring systems, this approach has been proposed by Mazaheri et al. [42,43]. ANN was used to predict the extreme values of a turret-moored FPSO under different metocean condition with specific configuration for the mooring system. The use of meta-models has been presented in [44-46] to obtain full timeseries of mooring line or riser tensions. Pina [44] use Neural Network with an "exogenous" model, he presented estimation of line tension of moorings in time series using NARX, and then compare it results with FE simulation.

Many study cases ware modelled using signal mirroring with some advantages; eliminate restriction of time-intervals phenomenon and increase accuracy by eliminating of fluctuations when signal is sharply increase or decrease, and faster convergence rates [4754]. Ha [47] use signal mirroring on Fourier Transform-based to quantify the experimental and calculation result show a significant improvement of the accuracy. Andrej [48] shows that Fast Fourier Transform by signal mirroring can contribute to the increase of the efficiently of the study when parameter is varied at a time. In this study, NARX model for floating structures has been performed with mirroring technique.

\section{Numerical modelling and NARX model}

This study was conducted to predict the six degrees of freedom of dynamic responses of floating structure due to regular and irregular waves. Neural Network model with NARX can predicts time series displacements on six degrees of freedom responses. The dataset used in this study using four different parameters; wave heights, wave periods, masses, regular and irregular waves. The available synchronized times step for each simulation with regular and irregular wave loads divide into three sets. About $75 \%$ data were used for training to give ANN model a large sampling, while $15 \%$ were used as validation to make sure the convergence not stop to a local value and the rest $10 \%$ were used as testing. The output for each simulation contains six degrees of freedom of dynamic responses of floating structure. For each of six degrees of freedom have total length of simulation 1200 seconds with $0.1 \mathrm{sec}$ per-step. Dynamic responses of floating structure will be the output of ANN model, while simulation time-step and wave parameters will be the input of ANN model.

In this work, neural network with a feed-forward multilayer is used. Previous parametric study investigated the use of more neurons could increase computation times [43]. However, in this study, since not significantly increase computation time to convergence, NARX model has 4 input features, 10 hidden layers, and one output layer are applied to get better results without specific studies about the performances. With such data will be normalized for the Neural Network process analysis because this method only 
recognizes the binary number is 0 to 1 . After that done the process of changing data from univariate to multivariate form for input and output data. Six degrees of freedom are recorded and trained using Neural Network, however only surge and heave are presented.

The data used in this study are the time series of dynamic responses of single floating structure with truncated cylinder of draft $0.8 \mathrm{~m}$ and diameter $2.5 \mathrm{~m}$. For this study, hydrodynamic coefficients for this geometry used example that have previously computed by Wamit. Physical, Numerical, and Neural Network model of cylinder is shown on Figure 1. Many parameters are used in this study; where $\mathrm{D}$ is diameter of cylinder, $\mathrm{h}$ is the height of cylinder, $\mathrm{K}$ and $\mathrm{C}$ are the stiffness and damping coefficient respectively. Matlab code was used to calculate the dynamic responses of the floating structure with variation of parameters. Wave parameters have amplitude 1 to $3 \mathrm{~m}$ with 0.1 interval, and wave period was 7 to 9 second with 0.1 interval. Different mass also applied to this study, mass used in this study are $1950 \mathrm{~kg}$ to $2500 \mathrm{~kg}$ with $50 \mathrm{~kg}$ interval.
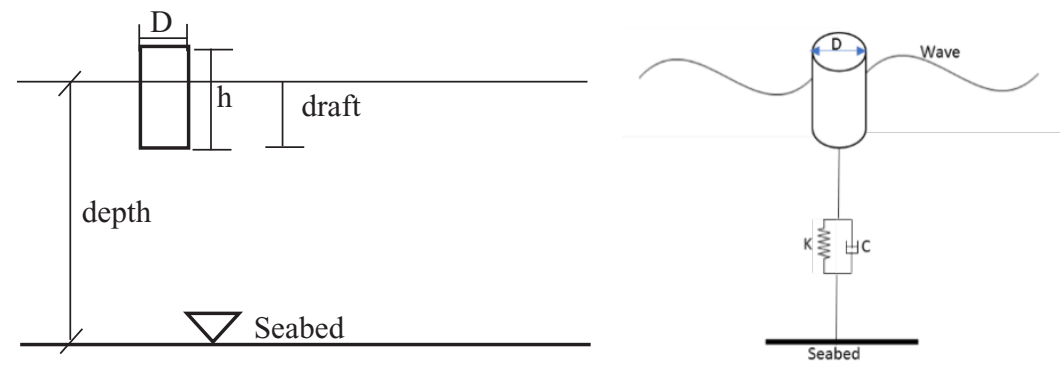

(a)

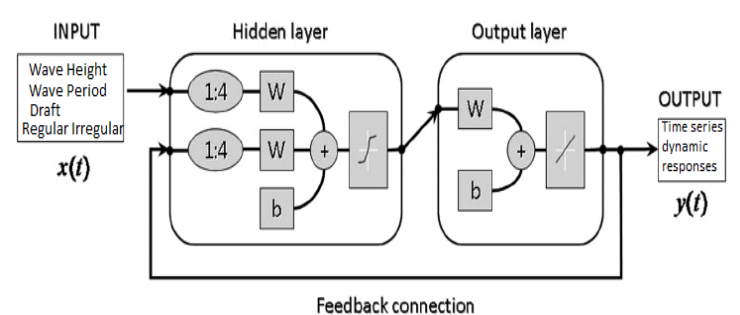

(b)

Fig. 1. Physical and Numerical Modeling (a) and NARX Model (b)

\section{Results and discussions}

\subsection{Motion time series}

The first model used is to analyse the parameters on Neural Network to find the smallest MSE. After performing Neural Network to predict dynamic responses of structure due to regular and irregular waves, both result will be compared with mirroring technique. From the analysis it is proven that the Mirroring Technique Algorithm against the Neural Network method can minimize the RMSE value so as to increase the accuracy of prediction. The performance of NARX model with and without mirroring technique are shown in table1. MSE (Mean Square Error) is quite good for all NARX model for heave and surge directions. 
Table 1. The performance statistics of NARX model

\begin{tabular}{|c|c|c|}
\hline \multirow{2}{*}{ Performance Statistics of ANN Models During Training, Testing and Validation } \\
\hline \multirow{2}{*}{ Performance Criteria } & Heave & Surge \\
\cline { 2 - 3 } & MSE & MSE \\
\hline Regular Wave & $3.68 \mathrm{E}-05$ & $1.51 \mathrm{E}-02$ \\
\hline Irregular Wave & $1.27 \mathrm{E}-04$ & $9.10 \mathrm{E}-03$ \\
\hline Regular Wave (mirroring) & $5.71 \mathrm{E}-08$ & $1.30 \mathrm{E}-03$ \\
\hline Irregular Wave (mirroring) & $1.86 \mathrm{E}-06$ & $3.50 \mathrm{E}-03$ \\
\hline
\end{tabular}

\subsection{Dynamic Responses Prediction with Regular Waves}

The first test was done by using regular wave as a load with different parameters such as wave periods, wave heights and drafts. Wave periods used in this model 8 to 10 secs and wave with 0.1 interval, while the wave heights varied from 1 to 3 secs with 0.1 interval. The results obtained using the numerical modelling with regular waves. Then NARX model using four input neurons with 10 hidden layers and one output neurons $(1: 4,1: 4,10)$ with $75 \%$ for testing, $15 \%$ for validation, and $10 \%$ for testing) is shown graphically in Figure 1. It was noted that the error (MSE) when using standard configuration to predict the actual responses of heave and surge directions were 3.68E-05 and $1.51 \mathrm{E}-02$ respectively. While prediction of responses in heave and surge direction using mirroring technique were $5.71 \mathrm{E}$ 08 and $1.30 \mathrm{E}-03$ respectively.

It is shown that the prediction using mirroring technique tends to have a better results compare to the standard configuration. The highest variance is on any end of input signal due to disconnected signal between input as shown in Figures 2 and 4 . It is obvious from Figures 3 and 5 that ANN prediction performs adequately but by using standard input configuration showed poor performance in between input series. Figures 3 and 5 show the error in the time series prediction in surge and heave direction for regular waves, the trends in the trained and predicted time series follow closely the trends of responses. Figures 6 and 8 show that the mirrored data of input contribute to increase the accuracy and performance in training process. Furthermore, mirroring data as new input in ANN shows the better MSE values and lower errors as shown in Figures 7 and 9.



Fig. 2. Surge responses of floating structure without mirroring technique for regular waves 




Fig. 3. Surge response errors without mirroring technique for regular waves

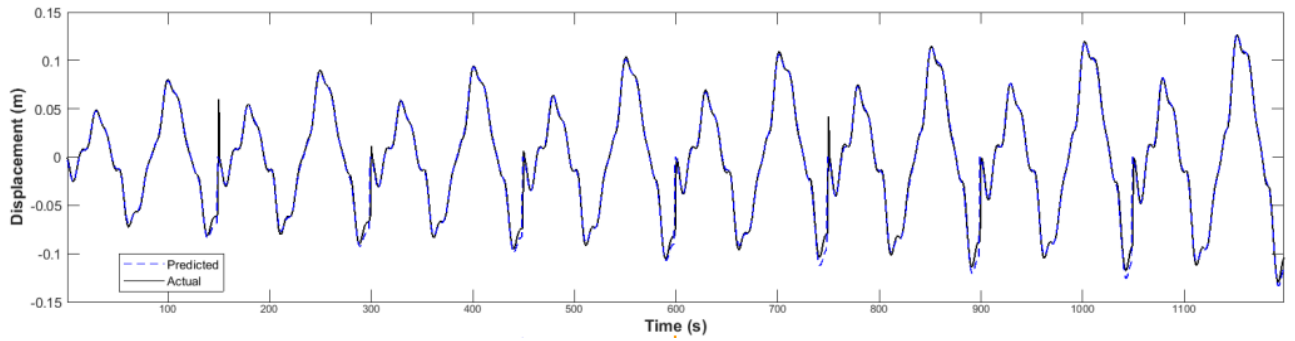

Fig. 4. Heave responses of floating structure without mirroring technique for regular waves

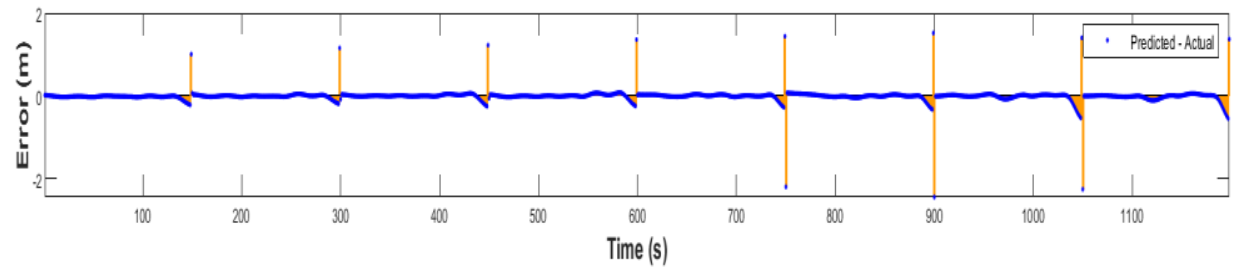

Fig. 5. Heave response errors without mirroring technique for regular waves

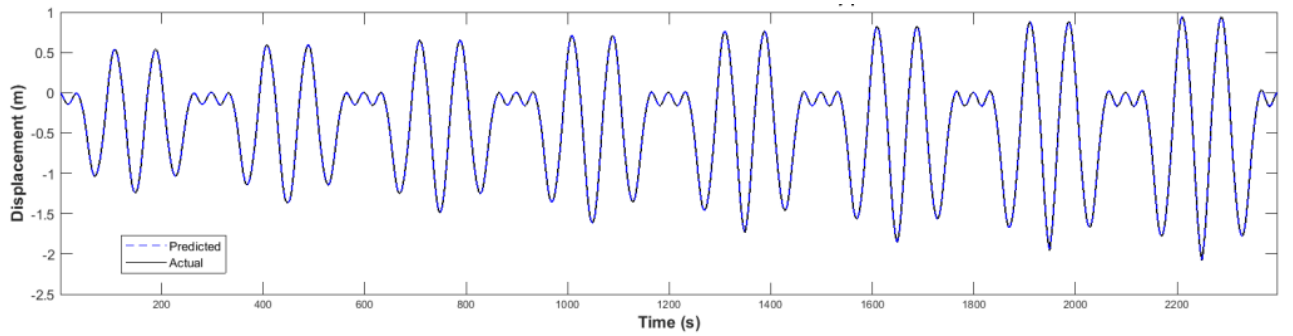

Fig. 6. Surge responses of floating structure with mirroring technique for regular waves



Fig. 7. Surge response errors with mirroring technique for regular waves 


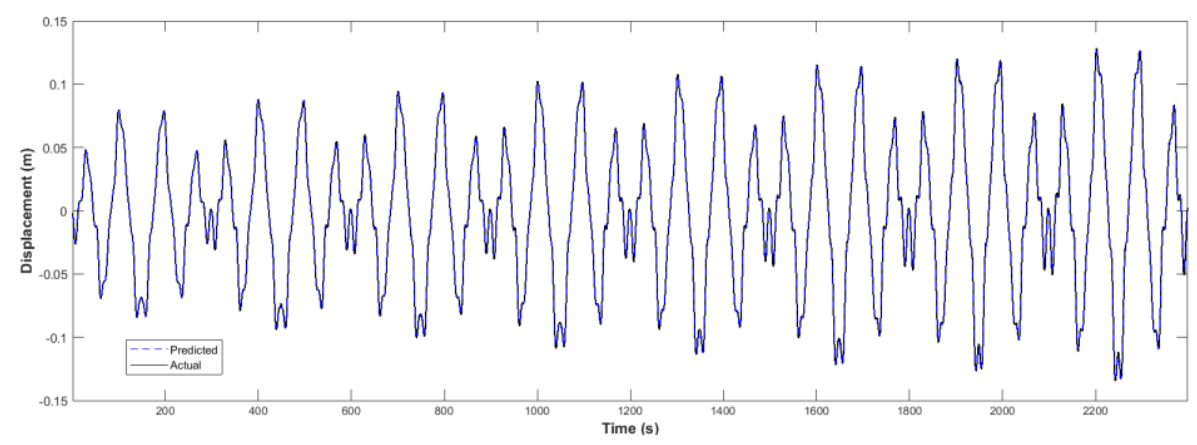

Fig. 8. Heave Responses of floating structure with mirroring technique for regular waves

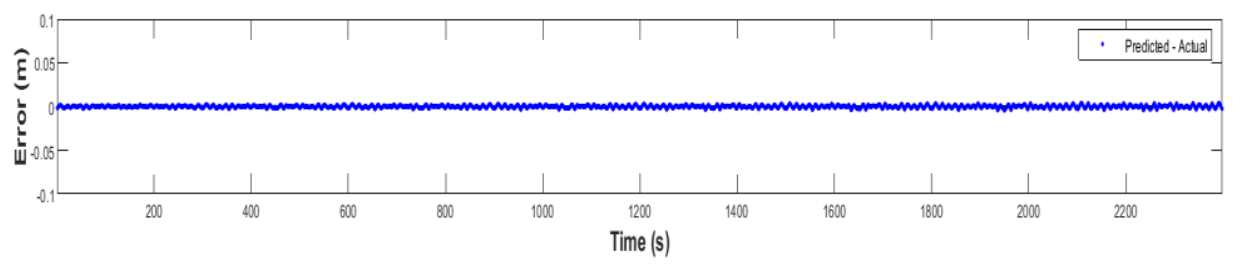

Fig. 9. Heave response errors with mirroring technique for regular waves

\subsection{Dynamic Responses Prediction with Irregular Waves}

In this section, the dynamic responses prediction of ANN model for irregular waves is discussed. Irregular waves use random value as an input, the ANN model can map this trend during ANN training. Using same configuration as used in regular waves, data divided into two sets, about $75 \%$ used for training, $15 \%$ used for validation, and the rest $10 \%$ used for testing.

Both for regular and irregular waves are tested using same number of neurons, the ANN performance decrease in irregular waves due to random input, but the prediction still performs well with MSE 1.27E-04 and 9.10E-03 for heave and surge directions respectively. The prediction of dynamic responses in surge and heave directions without mirroring technique are shown in Figures 10 and 12, while prediction errors of dynamic responses in surge and heave direction are shown in Figures 11 and 13. The prediction results presented in Figures 14 and 16 using mirroring technique is suitable for dynamic responses prediction in irregular waves with great improvement in accuracy. The prediction errors of dynamic responses using mirroring technique is shown in Figures 15 and 17. MSE for irregular waves using standard configuration and mirroring technique are 1.86E-06 and 3.50E-03 for heave and surge directions, respectively. The accuracy prediction using mirroring technique increased the MSE by more than 10 times. 


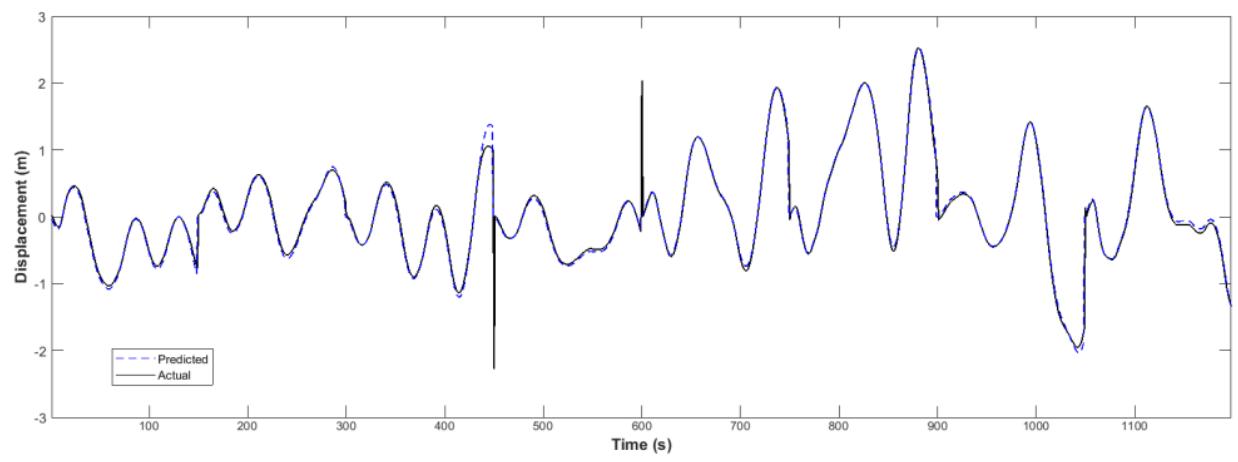

Fig. 10. Surge Responses of floating structure without mirroring technique for irregular waves



Fig. 11. Surge response errors without mirroring technique for irregular waves



Fig. 12. Heave Responses of floating structure without mirroring technique for irregular waves

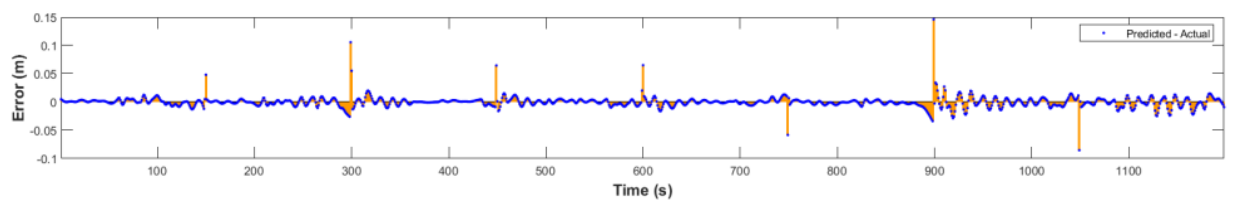

Fig. 13. Heave response errors without mirroring technique for irregular waves 


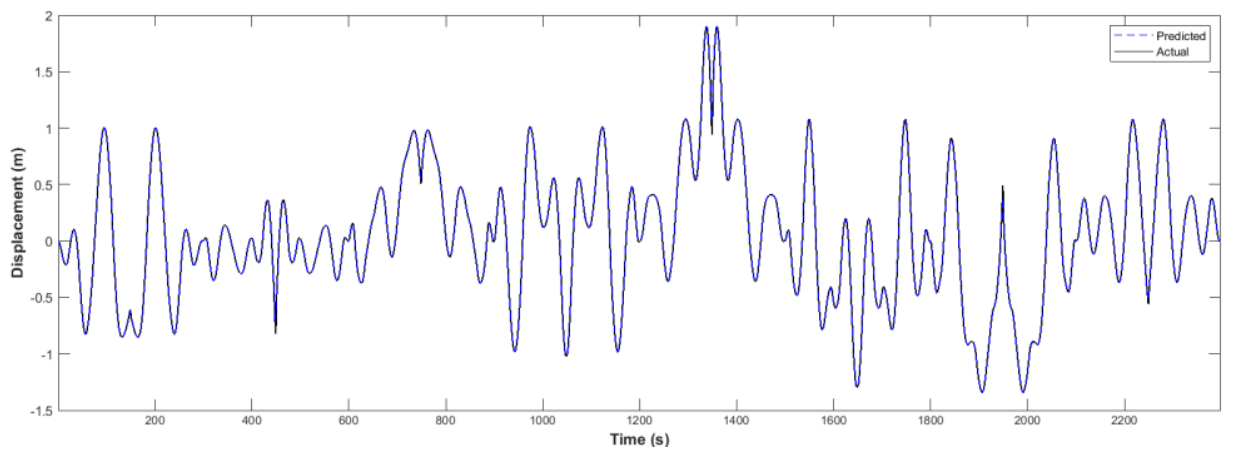

Fig. 14. Surge Responses of floating structure with mirroring technique for irregular waves

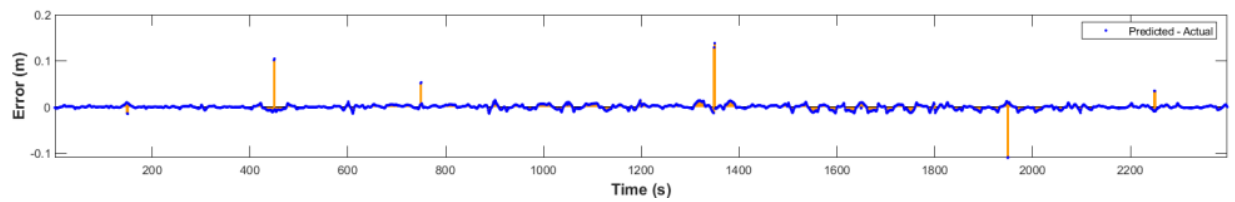

Fig. 15. Surge response errors with mirroring technique for irregular waves



Fig. 16. Heave Responses of floating structure with mirroring technique for irregular waves



Fig. 17. Heave response errors with mirroring technique for irregular waves

\section{Conclusions}

This study evaluates the feasibility of using Neural Network as a tool for prediction of dynamic responses of floating structures. The main conclusions extracted from the present study are as follows;

1.NARX, the nonlinear autoregressive network with exogenous inputs based nonlinear scheme, provide adequate estimations of dynamic responses of floating structure in random and regular wave on six degrees of freedoms. 
2.Recalling that NARX prediction model in general maybe strongly input-dependent, the results of parametric studies have led to mirrored data configuration that achieve substantially better than standard configuration, increasing accuracy by more than ten times especially for the prediction of heave displacements.

3. Neural Network with advance input configuration model may comprise a better alternative to replace full numerical model in future especially for screening purposes.

The authors would like to thank MOHE for funding the presentation of this paper at the conference using the project: FRGS 2015-1 (0153AB-K85), and Universiti Teknologi PETRONAS for the supports.

\section{References}

1. J. Wichers, A simulation ModeL for a single Point Moored Tanker, PhD Dissertation, Delft University, (1988).

2. J. M. Heurtier, P. Buhan, E. Fontane, C. Cunff, F Biolley and C. Berhault, CoupLed Dynamic Response of Moored FPSO with Risers, Proceedings of the Eleventh ISOPE Conference, Norway,I, pp 319 326, (2001)

3. C. Zhao, Y. Bai and Y. Shin, Extreme Response and Fatigue Damages for FPSO Structural AnaLysis, Proceedings of the Eleventh ISOPE Conference, Norway,I, pp $301-308,(2001)$

4. M. H. Kim, B. J. Koo, R. M. Mercier and E. G. Ward, Vessel/ Mooring/ Riser CoupLed Dynamic Analysis of a Turret - Moored FPSO Compared with OTRC Experiment, Ocean Engineering,32, pp 1780-1802, (2005)

5. G. Wang, L. Sun and S. Ma, Time Domain Analysis of FPSO Tanker Responses in Tandem Offloading Operation, Journal of Marine science Application,9, pp 200 - 207, (2010)

6. I. Catipovic, V. Coric and V. Vukcevic, Dynamics of FPSO with Polyester Mooring Lines, Proceedings of Twenty-second ISOPE conference, Greece, pp 996 - 1003, (2012)

7. A. Tahar and M. H. Kim, Coupled - Dynamic Analysis of Floating Structures with PoLyester Mooring Lines, Ocean Engineering,35, pp 1676 - 1685, (2008)

8. K. H. Kim and Y. Kim, Comparative Study on Ship Hydrodynamics Based on Newmann - Kelvin and Double Body Linearizations in Time Domain AnaLysis, ISOPE, 20(4) pp 265 - 274, (2010)

9. B. J. Koo and M. H. Kim, Hydrodynamic interactions and reLative motions of two fLoating pLatforms with mooring Lines in side - by - side offLoading operation, Applied Ocean Research,27, pp 292 - 310, (2005)

10. K. H. Kim, Kim Y. and Kim M. S., NumericaL AnaLysis on Motion Responses of Adjacent MuLtipLe FLoating Bodies by Using Rankine PaneL Method, ISOPE, (19)2, pp 90 - 96, (2009)

11. S. Yan., Q. W. Ma and X. Cheng, Fully NonLinear Hydrodynamic Interaction Between Two 3D FLoating Structures in CLose Proximity, ISOPE (21)3, pp 178 - 185, (2011)

12. Lee D. H. and Choi H. S., A Dynamic AnaLysis of FPSO - ShuttLe Tanker System, ISOPE,I, pp 302 - 307, (2000)

13. D. S. Qiao and J. P. Ou, Truncated ModeL Tests for Mooring Lines of a SemiSubmersibLe Platform and Its EquivaLent Compensated Method, Journal of Marine Science and Technology. 
14. 0. F. Waals and R. T. V. Radboud, Truncation Methods for Deep Water Mooring Systems for a catenary moored FPSO and a Semi Taut Moored Semi SubmersibLe, MARIN.

15. T. Fan, D. Qiao and J. Ou, Dynamic Effects of EquivaLent Truncated Mooring Systems for aSemi-Submersib Le PLatform, Brodogradnja/Shipbilding, 65,4, 2014.

16. K. Nam, D. Chang, K. Chang, T. Rhee and I. B. Lee, MethodoLogy of Liftcycle Cost with Risk Expenditure for Offshore Process at Conceptual Design Stage, Energy,36, pp 1554 - 1563, (2011)

17. I. Thalji, J. P. Liyanage and M. Hjollo, ScaLable and Customer Oriented Life CycLe Costing ModeL: A Case Study of an Innovative Vertical Axis Wind Turbine Concept (Case - VAWT), Proceedings of the Twenty - second ISOPE Conference, Rhodes, Greece, pp 423 - 425,( 2012)

18. L. C. Santos, G. P. Garcia and V. D. Casas, MethodoLogy to study the Life cycLe cost of floating offshore wind farms, Energy Procedia, pp 1- 8, (2013)

19. G. A. Grastos, H. N. Psaraftis and P. Zachariadis, Life CycLe Cost of Maintaining the Effectiveness of a Ship's Structure and Environmental Impact of Ship Design Parameters, RINA Conference on the Design and Operation of Bulk Carriers, Athens, Greece, pp 1 - 16, (2009)

20. S.F. Senra, B.P. Jacob, F.N. Corrêa, B.M. Jacovazzo, A.L. de Lima, T.A.G. de Lacerda, C.H. Fucatu, Assessment and calibration of numerical coupled models of a deep-draft semisubmersible platform based on model tests, in: Proceedings of the Twentieth (2010) International Offshore and Polar Engineering Conference, ISOPE 2010, Beijing, China, (2010)

21. H. Ormberg, K. Larsen, Coupled analysis of floater motion and mooring dynamics for a turret-moored ship, Appl. Ocean Res. 20 (1998) 55-67.

22. M.V. Rodrigues, F.N. Correa, B.P. Jacob, Implicit domain decomposition methods for coupled analysis of offshore platforms, Commun. Numer. Methods Eng. 23 (2007) 599-621, http://dx.doi.org/10.1002/cnm.945.

23. B.P. Jacob, R.A. Bahiense, F.N. Correa, B.M. Jacovazzo, Parallel implementations of coupled formulations for the analysis of floating production systems, part I: coupling formulations, Ocean Eng. $55 \quad$ 206-218, http://dx.doi.org/10. 1016/j.oceaneng.2012.06.019. (2012)

24. B.P. Jacob, L.D. Franco, M.V. Rodrigues, F.N. Correa, B.M. Jacovazzo, Parallel implementations of coupled formulations for the analysis of floating production systems, part II: domain decomposition strategies, Ocean Eng. 55 219-234, http://dx.doi.org/10.1016/j.oceaneng.2012.06.018. (2012)

25. B.P. Jacob, N.F.F. Ebecken, Adaptive time integration of nonlinear structural dynamic problems, Eur. J. Mech. A Solids 12 277-298. (1993)

26. B.P. Jacob, N.F.F. Ebecken, Towards an adaptive semi-implicit solution scheme for nonlinear structural dynamic problems, Comput. Struct. 52 495-504. (1994)

27. B.P. Jacob, N.F.F. Ebecken, An optimized implementation of the newmark/NewtonRaphson algorithm for the time integration of nonlinear problems, Commun. Numer. Methods Eng. 10 983-992. (1994)

28. F.N. Correa, B.P. Jacob, W.J. Mansur, Formulation of an efficient hybrid timefrequency domain solution procedure for linear structural dynamic problems, Comput. Struct. 88 (2010) 331-346, http://dx.doi.org/10.1016/j. compstruc..11.008 (2009) 
29. F.N. Correa, B.M. Jacovazzo, M.H.A. de Lima Jr., B.P. Jacob, A reduced integration method for the coupled analysis of floating production systems, Ocean Eng. 104422 436, http://dx.doi.org/10.1016/j.oceaneng.2015.05.033. (2015)

30. A.R.C. Giron, F.N. Correa, A.O.V. Hernandez, B.P. Jacob, An integrated methodology for the design of mooring systems and risers, Mar. Struct. 39 (2014) 395-423, http://dx.doi.org/10.1016/j.marstruc.2014.10.005.

31. S. Haykin, Neural Networks-A Comprehensive Foundation, Prentice Hall, New Jersey, (2001)

32. B. Widrow, D.E. Rumelhart, M.A. Lehr, Neural networks: applications in industry, business and science, Commun. ACM 37 (3) 93-105. (1994)

33. Z. Waszczyszyn, L. Ziemianski, Neural networks in mechanics of structures and materials - New results and prospects of applications, Comput. Struct. 79 2261-2276. (2001)

34. H. Adeli, Neural networks in civil engineering: 1989-2000, Comput. Aided Civ. Infrastruct. Eng. 16 126-142. (2001)

35. S.F. Yasseri, H. Bahai, H. Bazargan, A. Aminzadeh, Prediction of safe sea-state using finite element method and artificial neural networks, Ocean Eng. 37 200-207. (2010)

36. A.B. Mahfouz, Predicting the capability-polar-plots for dynamic positioning systems for offshore platforms using artificial neural networks, Ocean Eng. http://dx.doi.org/10.1016/j.ocean eng.2006.08.006. (2006)

37. D. Ok, Y. Pu, A. Incecik, Artificial neural networks and their application to assessment of ultimate strength of plates with pitting corrosion, Ocean Eng. 34 2222-2230, http://dx.doi.org/10.1016/j.oceaneng.2007.06.007. (2007)

38. L.M. Quéau, M. Kimiaei, M.F. Randolph, Artificial neural network development for stress analysis of steel catenary risers: sensitivity study and approximation of static stress range, Appl. Ocean Res. 48 148-161. (2014)

39. Y. Kim, Prediction of the dynamic response of a slender marine structure under an irregular ocean wave using the NARX-based quadratic Volterra series, Appl. Ocean Res. 49 (2015) 42-56, http://dx.doi.org/10.1016/j.apor..11.002. (2014)

40. Y. Kim, Finite memory quadratic Volterra model for the response prediction of a slender marine structure under a Morison load, J. Fluids Struct. 56 75-88. (2015)

41. S. Mazaheri, E. Mesbahi, M.J. Downie, A. Incecik, Seakeeping analysis of a turretmoored FPSO by using artificial neural networks, Procs. of OMAE03-22nd International Conference on Offshore Mechanics and Arctic Engineering (2003)

42. S. Mazaheri, M.J. Downie, Response-Based method for determining the extreme behaviour of floating offshore platforms, Ocean Eng. 32 363-393, http://dx.doi.org/10.1016/j.oceaneng.2004.08.004. (2005)

43. R. Guarize, N.A.F. Matos, L.V.S. Sagrilo, E.C.P. Lima, Neural networks in the dynamic response analysis of slender marine structures, Appl. Ocean Res. 29 191-198. (2007)

44. A.C. de Pina, A.A. de Pina, C.H. Albrecht, B.S.L.P. de Lima, B.P. BSLP, ANN-based surrogate models for the analysis of mooring lines and risers, Appl. Ocean Res. 4176 86, http://dx.doi.org/10.1016/j.apor.2013.03.003. (2013)

45. A.C. de Pina, C.H. Albrecht, B.S.L.P. de Lima, B.P. Jacob, Wavelet Network metamodels for the analysis of slender offshore structures, Eng. Struct. 68 71-84, http://dx.doi.org/10.1016/j.engstruct.2014.02.039. (2014) 
46. A.C. de Pina, B.F.M. Monteiro, C.H. Albrecht, B.S.L.P. de Lima, B.P. Jacob, ANN and wavelet network meta-models for the coupled analysis of floating production systems, Appl. Ocean Res. 48 21-32, http://dx.doi.org/10. 1016/j.apor.2014.07.009. (2014)

47. Tae Wook Ha, Jae Jun Jeong, Ki Yong Choi, Modification of the fast fourier transform-based method by signal mirroring for accuracy quantification of thermalhydraulic system code, Nuclear Engineering and Technology 49 1100-1108. (2017)

48. Andrej Prošek, et.al, Use of FFTBM by signal mirroring for sensitivity study, Annals of Nuclear Energy, 76 253-262. (2015)

49. Arindam Ghosh, et al. Theory of mirrored time domain sampling for NMR spectroscopy, Journal of Magnetic Resonance, Journal of Magnetic Resonance 213 4657. (2011)

50. Andrej Pro sek, et al. Quantitative assessment with improved fast Fourier transform based method by signal mirroring, Nuclear Engineering and Design 238 2668-2677. (2008)

51. Andrej Pro sek, et al. Quantitative assessment with improved fast Fourier transform based method by signal mirroring, Nuclear Engineering and Design 238 2668-2677. (2008)

52. Tae Wook Ha, et al. Modification of the fast fourier transform-based method by signal mirroring for accuracy quantification of thermal-hydraulic system code, Nuclear Engineering and Technology 49 1100e1108. (2017)

53. Dimo Brockhoff, et al. Mirrored Sampling and Sequential Selection for Evolution Strategies, PPSN 11-21. (2010)

54. Mahdi Saghafi, et al. Application of FFTBM with signal mirroring to improve accuracy assessment of MELCOR code. Nuclear Engineering and Design 308 238-251. (2016) 